Rev. Elet. em Gestão, Educação e Tecnologia Ambiental (e-ISSN: 2236-1170)

\title{
ANÁLISE DE RESULTADOS DE PEGADA HÍDRICA POR PAÍSES E PRODUTOS ESPECÍFICOS
}

\author{
George Scarpat Giacomin ${ }^{1}$, Alfredo Akira Ohnuma $\mathrm{Jr}^{2}$ \\ ${ }^{1}$ Mestrando em Tecnologia Ambiental na FAACZ, Autor, georgegiacomin@gmail.com \\ 2 Professor Titular do Mestrado Profissional em Tecnologia Ambiental, FAACZ, Orientador, akira@fsjb.edu.br.
}

http://dx.doi.org/10.5902/223611706721

\section{RESUMO}

A pegada hídrica é indicador ambiental que se concentra em avaliar as necessidades diretas e indiretas de água para sustentar o estilo de vida de uma pessoa, região, nação, empresa e produto. Este trabalho visa apresentar e avaliar resultados de pegadas hídricas por produto, indivíduo e nações, levando-se em consideração estimativas avaliadas por Mekonnen \& Hoekstra (2011), com base em sua composição (água virtual, água verde, água azul e água cinza) e fatores determinantes (volume e padrão de consumo, clima e práticas agrícolas). São avaliadas as necessidades diretas e indiretas do uso da água para sustentar o estilo de vida de um determinado país. Atualmente, estima-se que cada brasileiro consome anualmente cerca de $2027 \mathrm{~m}^{3}$ de água, enquanto que um norte-americano consome aproximadamente $2842 \mathrm{~m}^{3}$ e a pegada hídrica média mundial é de $1385 \mathrm{~m}^{3}$ /ano per capita (Mekonnen \& Hoekstra, 2011). Para o cálculo da pegada hídrica considera-se o consumo de água somado a água virtual importada, menos às águas de exportação. O trabalho apresenta valores médios por indivíduo de pegada hídrica de países desenvolvidos e em desenvolvimento como Itália (2303 m³/ano per capita) e Índia (1089 mªno per capita), conforme Mekonnen \& Hoekstra (2011). Além de valores médios para alguns produtos, como carne bovina com $16000 \mathrm{~L}$ de água para cada quilograma de carne (Hoekstra \& Chapagain, 2008). A concepção da pegada hídrica fornece instrumentos para analisar e compreender o modo de consumo de água na atualidade em diversas regiões do planeta, a fim de promover uma discussão sobre os padrões de uso sustentável da água.

Palavras-chave: Pegada hídrica, Consumo, Água virtual, Uso sustentável da água.

\section{ANALYSIS OF RESULTS OF WATER FOOTPRINT BY COUNTRY AND SPECIFIC PRODUCTS}

\section{ABSTRACT}

The water footprint is an indicator that focuses on environmental assess the direct and indirect needs water to sustain the lifestyle of a person, region, nation, company and product. This paper aims to present and evaluate results by product water footprints, individuals and nations, taking into account estimates evaluated by Mekonnen \& Hoekstra (2011), based on their composition (virtual water, green water, blue water and gray water) and factors (volume and patterns, climate and agricultural practices). Needs are assessed direct and indirect water use to sustain the lifestyle of a particular country. Currently, it is estimated that every American consumes annually about $2027 \mathrm{~m}^{3}$ of water, while an American consumes approximately $2842 \mathrm{~m}^{3}$ and the global average water footprint is $1385 \mathrm{~m}^{3}$ /year per capita (Mekonnen \& Hoekstra, 2011). To calculate the water footprint considers the consumption of water plus the virtual water import, export less to the waters. The work presents the mean values for individual water footprint of developed and 
Rev. Elet. em Gestão, Educação e Tecnologia Ambiental (e-ISSN: 2236-1170)

developing countries such as Italy (2303 $\mathrm{m}^{3} /$ year per capita) and India (1089 $\mathrm{m}^{3} /$ year per capita), as Mekonnen \& Hoekstra (2011). In addition to average values for some products, like beef with $16000 \mathrm{~L}$ of water for every kilogram of beef (Chapagain \& Hoekstra, 2008). The concept of water footprint provides tools to analyze and understand the way of water consumption today in several regions of the planet in order to promote a discussion about the standards of sustainable water use.

Key-words: Water footprint, consumption, Virtual Water, Sustainable Water Use.

\section{INTRODUÇÃO}

Provavelmente, por ocupar dois terços da superfície da Terra, a água foi considerada ao longo dos séculos um recurso infinito. No entanto a cada dia se percebe que a quantidade de água existente não significa que esta seja própria para o consumo humano. $\mathrm{O}$ aumento do consumo, 0 elevado grau de urbanização e o aumento populacional resultam em uma diversidade de impactos que exigem diferentes tipos de avaliação, novas tecnologias de monitoramento, avanços tecnológicos no tratamento e gestão das águas, além de uma maior conscientização ambiental. Os resultados de todos estes impactos são muito severos para a população humana, afetando todos os aspectos da vida diária das pessoas, a economia regional e nacional e a saúde humana. Estas conseqüências podem ser resumidas em: a) degradação da qualidade da água superficial e subterrânea; b) aumento das doenças de veiculação hídrica e impactos na saúde humana; c) diminuição da água disponível per capita; d) aumento no custo da produção de alimentos; e) impedimento ao desenvolvimento industrial e agrícola e comprometimento dos usos múltiplos e f) aumento dos custos de tratamento de água. (TUNDISI, 2003)

Neste contexto se destaca a Agenda 21, que foi criada como um dos principais resultados da conferência Eco-92 ou Rio-92, ocorrida no Rio de Janeiro, em 1992. É um programa de ação, baseado num documento de 40 capítulos, que se constitui na mais ousada e abrangente tentativa já realizada, em promover, em escala planetária, um novo padrão de desenvolvimento, conciliando métodos de proteção ambiental, justiça social e eficiência econômica. Trata-se, portanto, de um documento consensual resultante de uma série de encontros promovidos pela Organização das Nações Unidas (ONU), com o tema "Meio Ambiente e suas Relações com o Desenvolvimento". Em seu Capítulo 18 - "Proteção da Qualidade e do Abastecimento dos Recursos Hídricos: Aplicação de Critérios Integrados no Desenvolvimento, Manejo e Uso dos Recursos Hídricos", a Agenda 21, trata de um elemento essencial para que haja vida no planeta Terra: a água. O objetivo geral é assegurar a oferta de água de boa qualidade para todos os habitantes, mantendo as funções hidrológicas, biológicas e químicas dos ecossistemas, adaptando as atividades do homem aos limites da natureza e lutando para combater as enfermidades ligadas a água.

Alguns eventos agravam o cenário tanto da oferta como da demanda de água doce no mundo, tais como o crescimento demográfico associado a padrões de consumo não sustentáveis. Estima-se que a população humana aumentou três vezes no decorrer do século XX, passando de 2 para 6 bilhões de habitantes. Nesse mesmo período, a demanda de água aumentou sete vezes, isto é, passou de $580 \mathrm{~km}^{3} /$ ano para aproximadamente $4.000 \mathrm{~km}^{3} /$ ano. Esses dados tornam-se relevantes na medida em que é previsto que a população mundial estabilize-se, por volta do ano 2050, entre 10 e 12 bilhões de habitantes, o que representa cerca de 5 bilhões a mais que a população atual. Outro fator que agrava o cenário da utilização das águas no mundo é a gestão 
Rev. Elet. em Gestão, Educação e Tecnologia Ambiental (e-ISSN: 2236-1170)

ineficiente dos recursos hídricos em basicamente todas as atividades antrópicas, como ocorre na agricultura, na indústria e nos sistemas de abastecimento público de países, onde o desperdício de água, como em algumas regiões brasileiras (Região Sul, Sudeste e Centro-oeste, por exemplo), é superior a 60\%. (OMM/UNESCO, 1997 apud ANEEL/ANA, 2001.)

Nos últimos 20 anos têm sido utilizadas várias abordagens que constroem em torno da água pressupostos econômicos e políticos para classificar, explicar e enfrentar a escassez e a poluição da água no mundo. Nessa perspectiva, existem propostas de Gestão e Controle que tem se apresentado como possibilidades de resolução de futuros ou atuais conflitos acerca do uso, quantidade e qualidade da água. Com base nessa proposição econômica emerge o conceito da água como um bem econômico e, portanto, passível de uma política econômica e social específica que vise atender às necessidades e demandas da sociedade. Partindo deste princípio, é vital reconhecer inicialmente o direito básico de todos os seres humanos do acesso ao abastecimento e saneamento a custos razoáveis. O erro no passado de não reconhecer o valor econômico da água tem levado ao desperdício e usos deste recurso de forma destrutiva ao meio ambiente. $O$ gerenciamento da água como bem de valor econômico é um meio importante para atingir o uso eficiente e equitativo, e o incentivo à conservação e proteção dos recursos hídricos. (UERJ, s.d.).

A partir de uma perspectiva sobre os recursos hídricos, todos os aspectos da produção e do comércio nos quais a água esteja envolvida passam a requerer uma nova contextualização. Com isso surge um novo conceito muito importante - o de "Água Virtual", de autoria do professor britânico John Anthony Allan, que em 1993, apresentou ao mundo um modo de calcular a água efetivamente envolvida nos processos produtivos, que antes não era contabilizada. Calcular os volumes da água virtual envolvidos na produção de um bem, produto ou serviço é muito complexo, já que, "para estimar estes valores, deve-se considerar a água envolvida em toda a cadeia de produção, assim como, as características específicas de cada região produtora, além das características ambientais e tecnológicas." (CARMO et al, 2007).

Após uma década, surge também outro termo muito relevante, o conceito de "Pegada hídrica" que foi introduzido pelo engenheiro hídrico holandês Arjen Hoekstra, em 2002. Este conceito teve como objetivo criar um indicador de consumo de água que contabilizasse a quantidade de água utilizada na produção de bens e serviços consumidos pelos habitantes de um país ou região, levando em consideração os fluxos com outros países, relacionando água ao consumo. (HOEKSTRA et al, 2004) A pegada hídrica de um indivíduo, empresa ou nação é definida como a quantidade total de água potável que é utilizada para produzir os bens e serviços consumidos pelo indivíduo, empresa ou nação.

É no sentido de mensurar a quantidade de água envolvida em toda a cadeia de produção, de considerar as características especificas de cada região produtora e as características ambientais e tecnológicas que a concepção de pegada hídrica se torna relevante, pois se faz necessário perseguir os passos e etapas do processo produtivo avaliando detalhadamente cada elemento, os impactos e os usos dos recursos hídricos envolvidos no processo como um todo, desde sua matéria-prima básica até o consumo energético (CHAPAGAIN e HOEKSTRA, 2004).

\section{OBJETIVO}

Este trabalho visa analisar os resultados principais de pegadas hídricas por produto, indivíduo e nações como forma de ampliar a conscientização pelo uso da água, levando-se em consideração estimativas avaliadas por Hoekstra \& Chapagain (2007) e Mekonnen \& Hoekstra (2011). Pretende-se também apresentar os conceitos primordiais acerca do termo pegada hídrica, 
Rev. Elet. em Gestão, Educação e Tecnologia Ambiental (e-ISSN: 2236-1170)

em sua composição (água virtual, água verde, água azul e água cinza) e fatores determinantes (volume e padrão de consumo, clima e práticas agrícolas).

\section{METODOLOGIA}

Utilizam-se neste artigo critérios metodológicos baseados no levantamento de dados e informações disponíveis na literatura especializada, a fim de permitir uma reflexão crítica sobre as potencialidades, riscos e alternativas relacionadas à conscientização do uso da água por meio da socialização do conceito de pegada hídrica.

A metodologia utilizada compreende análise dos estudos principais realizados pela Water Footprint Network, considerando os dados obtidos de pegada hídrica por nações, produtos e indivíduo. Basicamente, para a análise dos dados, foram considerados quatro elementos ou fatores fundamentais e determinantes para os valores estimados de pegada hídrica, sendo:

- volume de consumo relacionado com o PIB,

- padrões de consumo diversos,

- condições ambientais,

- uso da água.

Os valores são apropriados para um mapeamento global (por nações) e para uma classificação unitária (por produtos selecionados). A discussão dos resultados tem como base: o desenvolvimento dos países e o teor de água virtual, principalmente no quesito "alimentação".

Para enriquecer as análises foram consideradostambém os princípios básicos da educação ambiental, a partir da formulação da Agenda 21, que em seu Capítulo 18 se refere à proteção da qualidade e abastecimento dos recursos hídricos com a aplicação de critérios integrados que envolvam seu desenvolvimento, manejo e uso.

\section{A IMPORTÂNCIA DA PEGADA HÍDRICA}

A pegada hídrica é um indicador que permite monitorar os efeitos da escassez de água, podendo ser útil como ferramenta de avaliação na gestão das águas. Trata-se de um conceito facilitador enquanto indicador quantitativo capaz de acessar não somente os volumes de água consumidos por região, mas também o período em que ocorre o consumo de água. A pegada hídrica prevê dessa forma uma possibilidade de gestão mais adequada dos recursos hídricos. Assim, pode-se evitar a exploração nos locais onde a água é mais escassa e direcionando o consumo para as regiões do planeta onde é mais abundante.

A Pegada Hídrica pode ser considerada um indicador da apropriação dos recursos hídricos, em oposição ao conceito padrão de simples mensuração da extração de água por três motivos: (HOEKSTRA et al 2007)

- Contabiliza a água de chuva e o volume de água poluído por efluentes e não apenas a captação de água superficial ou subterrânea.

- Considera o uso da água também ao longo de toda a cadeia produtiva.

- Desconta a água que for retornada para o local de captação com boa qualidade.

O conceito do termo "água virtual" refere-se ao volume de água contida apenas no produto, enquanto o termo "pegada hídrica" refere-se não apenas ao volume, mas também o tipo de água que foi usada (água verde, azul e cinza) e para onde e quando a água foi usada. A pegada hídrica de um produto é, portanto, um indicador multidimensional, ao passo que o teor de "água virtual" ou "água embutida" se referem a um só volume. (HOEKSTRA e HUNG, 2005) 
Rev. Elet. em Gestão, Educação e Tecnologia Ambiental (e-ISSN: 2236-1170)

O uso do termo "pegada hídrica" se refere a um escopo mais amplo. O volume é apenas um aspecto do uso da água, sendo o local, o tempo de uso da água e o tipo de água utilizada, tão importantes quanto. Soa estranho falar sobre o conteúdo de água virtual do consumidor ou do produtor. Usa-se o termo "água virtual" no âmbito de fluxos internacionais (ou inter-regional) de água virtual. (HUNG et al 2005) Neste contexto, pode-se falar sobre a exportação ou importação de água virtual, ou em geral, sobre os fluxos ou comércio de água virtual. O comércio internacional de alimentos e mercadorias implica num fluxo de água virtual entre os países.

Entender a importância da pegada hídrica é fundamental para compreender que a maior parte da água que uma pessoa consome em seus hábitos diários não vem das torneiras de casa, mas sim dos produtos que ela utiliza e consome. Aí estão incluídos desde a precipitação das chuvas nas regiões de produção agrícola até os litros de água consumidos para a produção industrial.

Quando, por exemplo, uma camisa de algodão é vendida de um país para outro, entendese que a água utilizada em sua fabricação também foi exportada. (HOEKSTRA et al 2007) O mesmo ocorre com carregamentos de soja, minério de ferro e tantas outras mercadorias. Para países com escassez de água, pode ser interessante a importação de água virtual - por meio da importação de mercadorias que consomem muita água em sua produção. Desta forma, eles podem aliviar as pressões sobre suas próprias fontes de água.

O resultado da escassez hídrica em algumas partes do planeta é um comércio mundial de água, na forma de bens e produtos. Os países e regiões que dispõem de água produzem bens para atender aqueles onde ela é escassa. Esse sistema passa a representar um problema quando as regiões produtoras, por falta de mecanismos adequados de gestão de seus recursos hídricos, passam a explorá-los em um ritmo superior à capacidade de regeneração do ambiente local. (CHAPAGAIN et al 2004)

Globalmente, a água é poupada se produtos agrícolas são comercializados de regiões com alta produtividade e que requerem menos água para produção, para aquelas com baixa produtividade e que necessitam de muita água em sua produção. Neste sentido, se países importadores produzissem internamente todos os produtos agrícolas importados, isto exigiria $1600 \times 10^{9} \mathrm{~m}^{3}$ de água por ano, no entanto, os produtos são produzidos com apenas $1200 \times 10^{9}$ $\mathrm{m}^{3}$ /ano nos países exportadores, economizando recursos hídricos globais em aproximadamente 400 bilhões $\mathrm{m}^{3}$ /ano. (WWF, 2010).

A pegada hídrica global relacionada à produção agrícola e industrial e abastecimento doméstico de água para o período 1996-2005 foi encontrado para ser $9087 \mathrm{Gm}^{3}$ /ano. (MEKONNEN e HOEKSTRA, 2011) A agricultura é o setor com maior gasto de água, estima-se que para o período entre 1996 e 2005, ela responda por 92\% do consumo de água total no planeta, superando de longe o volume gasto no setor industrial com $4,4 \%$ e o consumo doméstico com 3,6\%. O tamanho da pegada hídrica global é influenciado principalmente pelo consumo de alimentos e outros produtos agrícolas. (HOEKSTRA e MEKONNEN, 2012).

\section{A PEGADA HÍDRICA DOS PAÍSES}

Em termos totais, a China é o país com a maior pegada hídrica de consumo no mundo, com uma pegada hídrica total de $1368 \mathrm{Gm}^{3}$ /ano, seguido pela Índia e os EUA com $1145 \mathrm{Gm}^{3}$ /ano e $821 \mathrm{Gm}^{3}$ /ano, respectivamente. Obviamente, os países com grandes populações têm uma pegada hídrica grande. Por isso, é mais interessante observar a pegada hídrica per capita. (MEKONNEN e HOEKSTRA, 2011) 
Rev. Elet. em Gestão, Educação e Tecnologia Ambiental (e-ISSN: 2236-1170)

Os quatro principais fatores de determinação da pegada hídrica de um país são: o volume de consumo (em relação ao Produto Interno bruto - PIB), o padrão de consumo (por exemplo, alto e baixo consumo de carne), as condições climáticas (condições de crescimento das culturas agrícolas) e práticas agrícolas (uso eficiente da água). A influência desses indicadores faz com que a pegada hídrica varie de país para país. Isso pode ser observado na tabela 1 , que relaciona o aumento do poder aquisitivo com o aumento do consumo de carne.

Tabela 1 - Crescimento do poder aquisitivo e o consumo de carnes

\begin{tabular}{|c|c|c|}
\hline Ano & PIB (US\$/per capita) & Consumo de Carne (Kg/pessoa/ano) \\
\hline 1961 & 2.676 & 23,1 \\
\hline 1971 & 3.714 & 27,8 \\
\hline 1981 & 4.376 & 30,8 \\
\hline 1991 & 4.992 & 34,4 \\
\hline 2001 & 5.611 & 38,6 \\
\hline 2030 & 7.600 & 45,3 \\
\hline
\end{tabular}

Fonte: ROPPA (2006)

A pegada hídrica média global relacionada com ao consumo é de $1385 \mathrm{~m}^{3} /$ ano per capita no período 1996-2005. O consumidor dos Estados Unidos tem pegada hídrica média de 2842 $\mathrm{m}^{3}$ /ano per capita, enquanto os cidadãos na China e Índia têm pegada hídrica de 1071 e 1089 $\mathrm{m}^{3}$ /ano per capita, respectivamente. (HOEKSTRA e MEKONNEN, 2012)

Os países industrializados têm pegada hídrica na faixa de $1250-2850 \mathrm{~m}^{3} /$ ano per capita, enquanto os países em desenvolvimento mostram uma variação maior de $550-3800 \mathrm{~m}^{3} / \mathrm{ano}$ per capita, como pode ser observado na Figura 1.

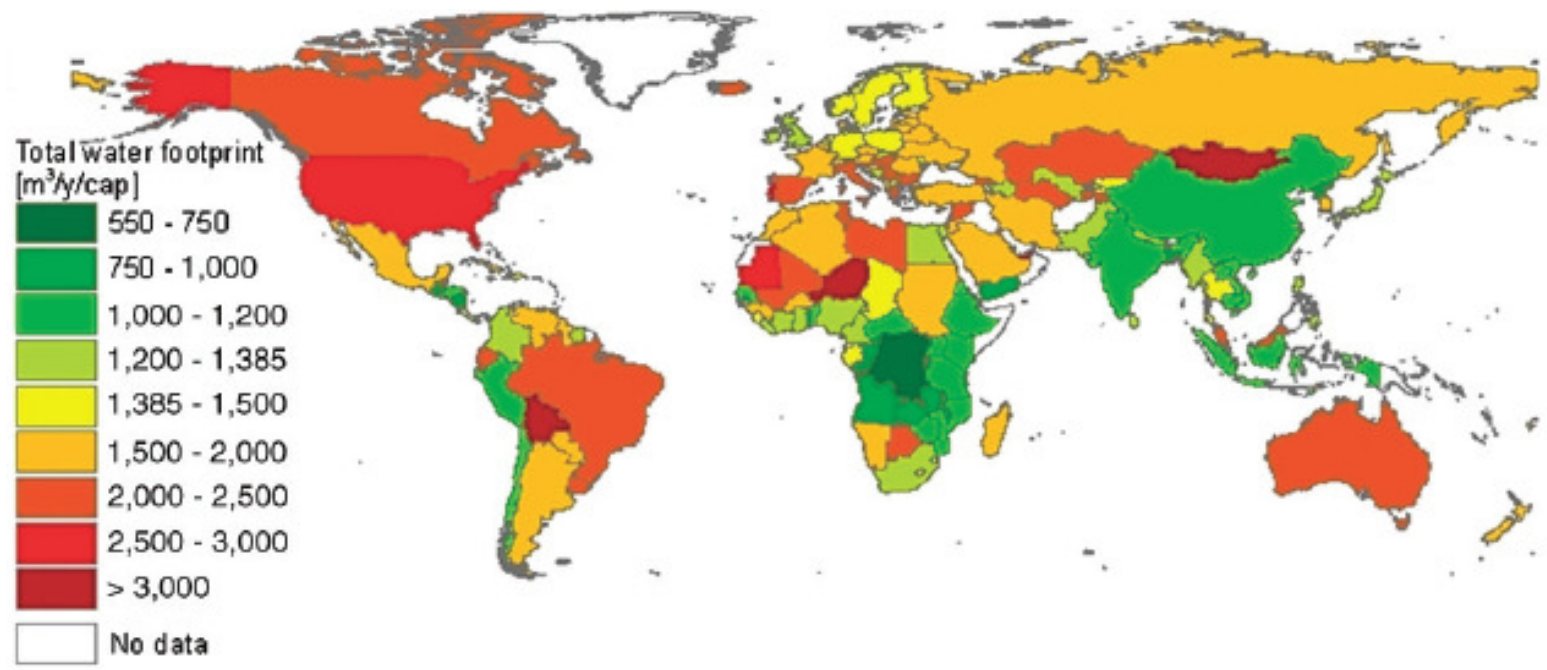

FIGURA 1 - Pegada hídrica média nacional per capita $\left(\mathrm{m}^{3} /\right.$ ano per capita) no período entre 1996 e 2005. Países em verde tem a pegada hídrica média menor que a média global. Países em amarelo e vermelho têm pegada hídrica média acima da média global. (HOEKSTRA e MEKONNEN, 2012) 
Rev. Elet. em Gestão, Educação e Tecnologia Ambiental (e-ISSN: 2236-1170)

Outro fator que influencia na alta dos valores de pegada hídrica é o consumo de água por unidade de produto, por país. Como pode ser identificado na tabela 2, nos EUA, a pegada hídrica média de um quilo de carne bovina consumida é $14500 \mathrm{~m}^{3} /$ ton, enquanto no Reino Unido este é $9900 \mathrm{~m}^{3} /$ ton. Enquanto na Bolívia, por exemplo, o consumo de carne é de 1,3 vezes a média global, mas a pegada hídrica por tonelada de carne é de cinco vezes a média global.

Tabela 2 - Relação entre Consumo de carne, Pegada Hídrica da Carne por país e Pegada Hídrica por país.

\begin{tabular}{|c|c|c|c|}
\hline País & $\begin{array}{c}\text { Consumo de Carne } \\
\text { (Kg/pessoa/ano) }\end{array}$ & $\begin{array}{c}\text { Pegada Hídrica da } \\
\text { Carne }\left(\mathbf{m}^{\mathbf{3}} \mathbf{\text { ton }}\right)\end{array}$ & $\begin{array}{c}\text { Pegada Hídrica por habitante } \\
\text { ( } \mathbf{m}^{\mathbf{3}} \text { /ano } \text { per capita }\end{array}$ \\
\hline EUA & 43 & 14500 & 2842 \\
\hline Brasil & 32 & 19400 & 2027 \\
\hline México & 23 & 17500 & 1978 \\
\hline Reino Unido & 18 & 9900 & 1258 \\
\hline Ucrânia & 10 & 12600 & 1575 \\
\hline China & 5 & 13700 & 1071 \\
\hline Bolívia & 12 & 77000 & 3468 \\
\hline Média Mundial & $\mathbf{9}$ & $\mathbf{1 5 4 0 0}$ & $\mathbf{1 3 8 5}$ \\
\hline
\end{tabular}

Fonte: Adaptada de MEKONNEN e HOEKSTRA (2011) e ROPPA (2006)

Mekonnen e Hoekstra (2010) mostraram que a pegada hídrica de qualquer produto de origem animal é maior do que a pegada hídrica de um produto agrícola, comparando-se com valor nutricional equivalente. ERCIN et al (2011) ilustra isso comparando a pegada hídrica de dois produtos de soja com dois produtos de origem animal equivalentes. Chegando a valores de $1 \mathrm{~L}$ de leite de soja produzido na Bélgica tinha uma pegada hídrica de aproximadamente $300 \mathrm{~L}$ água, enquanto que a pegada hídrica de $1 \mathrm{~L}$ de leite de vaca era mais do que 3 vezes maior. Outro exemplo que ilustra bem esta situação são os valores encontrados na pegada hídrica de um hambúrguer de soda de 150 g produzido na Holanda que consome cerca de 160 L de água, enquanto que a pegada hídrica média de um hambúrguer de carne de $150 \mathrm{~g}$ é quase 15 vezes maior.

Em pesquisa publicada em 2011, Arjen Y. Hoekstra e Mesfin M. Mekonnen mostram que cerca de $27 \%$ da pegada hídrica da humanidade está relacionada com a fabricação de produtos de origem animal. Apenas $4 \%$ da pegada hídrica da humanidade se relaciona com o uso da água em casa. Isto significa que se as pessoas quiserem reduzir sua pegada hídrica, elas devem olhar criteriosamente para sua dieta alimentar em vez de seu uso de água na cozinha, banheiro e jardim, por exemplo.

As estimativas sobre quanto se gasta de água para produção dos alimentos e alguns produtos são apresentados na Figura 2, ressaltando que são valores médios tendo em vista a grande variabilidade que existe em termos ambientais e de variedade de produtos. 
Rev. Elet. em Gestão, Educação e Tecnologia Ambiental (e-ISSN: 2236-1170)

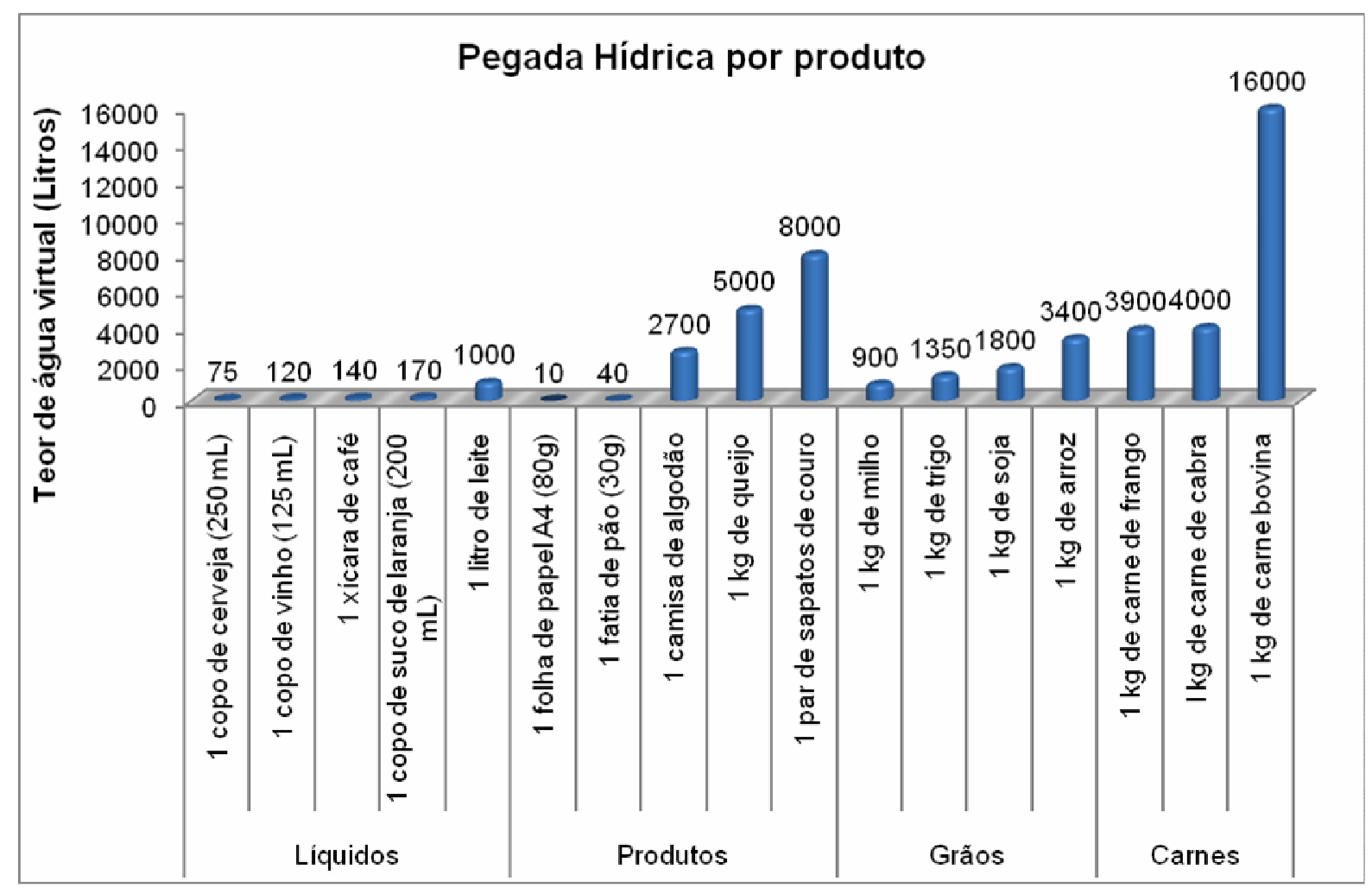

FIGURA 2 - Pegada hídrica média global de alguns produtos selecionados, por unidade de produto. Fonte: Water Footprint Network

A discussão sobre pegada hídrica abre espaço também para questionamentos ainda mais profundos. Um dos mais relevantes, diz respeito à produção de alimentos, discutindo a quantidade de água empregada na produção e o significado dessa produção em termos nutricionais. Uma das principais referências nessa discussão são David Pimentel, Bonnie Berger, David Filiberto, Michelle Newton, n, Benjamin Wolfe, Elizabeth Karabinakis, Steven Clark, Elaine Poon, Elizabeth Abbett e Sudha Nandagopa (2004) que defendem como questão central a possibilidade de diminuição significativa da demanda de água a partir de modificações na dieta alimentar, o que está presente em vários textos de sua autoria, nos quais chama atenção para o volume elevado de água que se gasta na produção de alimentos, atentando especificamente para o fato de que a produção de carne é um dos principais consumidores de água.

Os autores confirmam a necessidade de se reestruturar o cardápio, de maneira que ele seja mais "sustentável", privilegiando os produtos que exigem menos água para sua produção. Dessa maneira, um prato com batata e frango, por exemplo, exige muito menos água para sua obtenção do que um prato com arroz e bife bovino. Em cada cultura é possível perceber diferentes pratos típicos, relacionados a rituais e manifestações culturais específicas. Ao longo das últimas duas décadas observa-se uma tendência ao crescimento de um modelo de alimentação baseado em "fast food", que prioriza os hambúrgueres compostos de pão e carne bovina. Além de suas insuficientes qualidades nutricionais esse tipo de alimentação demanda muitos recursos hídricos, significando mais um elemento a ser considerado quando se observa a propagação desse tipo de alimentação por todo o planeta. 
Rev. Elet. em Gestão, Educação e Tecnologia Ambiental (e-ISSN: 2236-1170)

\section{CONSIDERAÇÕES FINAIS}

Nota-se uma disparidade global entre valores de pegada hídrica distribuídos principalmente em função do desenvolvimento econômico da nação. Países com PIB elevado tendem a maiores padrões de consumo e consequentemente, maiores taxas de pegada hídrica. Levando-se em consideração o maior poder aquisitivo avaliado pelo crescimento econômico, maiores são as possibilidades de consumo por produtos.

Observa-se que os países industrializados tem pegada hídrica per capita na faixa de 1250 $2850 \mathrm{~m}^{3}$ /ano. O Reino Unido, com uma pegada hídrica de $1258 \mathrm{~m}^{3} / \mathrm{ano}$, está no limite inferior desta faixa, enquanto os EUA, com uma pegada hídrica de $2.842 \mathrm{~m}^{3} / \mathrm{ano}$, está no limite superior. As diferenças podem ser parcialmente explicadas por diferenças no padrão de consumo. A pegada hídrica per capita dos países em desenvolvimento varia muito mais do que para os países industrializados. Os valores variam na faixa de 550-3800 $\mathrm{m}^{3} /$ ano per capita. Na extremidade inferior está a República Democrática do Congo, com $552 \mathrm{~m}^{3} /$ ano per capita, enquanto na extremidade superior está a Bolívia (3468 mª $/$ ano per capita) e Níger (3519 mªno per capita). Nos países em desenvolvimento a pegada hídrica varia, geralmente, não por causa de seu grande consumo relativo de água - embora um consumo de carne relativamente grande pode desempenhar um papel importante no aumento da pegada hídrica - mas por causa das baixas produtividades de água, isto é, grandes pegadas hídricas por tonelada de produto consumido. Outro fator a ser destacado são os baixos rendimentos na produção agrícola e as elevadas taxas de evapotranspiração dos países.

Além de reduzir a demanda de água em escala global, o cenário planetário de escassez de água sugere que devemos orientar nosso consumo para o local e a época onde não faz tanta falta. Esse é o cenário para o qual foi criado o conceito da pegada hídrica. Trata-se de um mecanismo de transparência. A ideia é que, com o auxilio da educação ambiental, os governos, as empresas, as comunidades e os consumidores possam reduzir o impacto de seus consumos, se conhecerem a pegada hídrica dos produtos que consomem e produzem e fizerem melhores escolhas.

\section{RECOMENDAÇÕES}

Torna-se necessário aprofundar os conhecimentos sobre pegada hídrica com estudos para determinar a demanda de água para outros produtos de forma regional, assim como para indivíduos. Sugere-se estimar o cálculo de pegada hídrica, por exemplo, para batatas produzidas na região do estado do Espírito Santo ou outro produto agrícola.

\section{AGRADECIMENTOS}

À FAPES (Fundação de Amparo à Pesquisa do Espírito Santo), conforme Edital Fapes N. 003/2010 por conceder bolsa de estudo para dedicação integral ao curso de Pós-Graduação em Mestrado Profissional em Tecnologia Ambiental na instituição Faculdade de Aracruz (Faacz). À Fundação São João Batista (FSJB) por oportunizar os estudos e as pesquisas no âmbito dos cursos de pós-graduação strictu senso. 
GIACOMIN \& OHNUMA, v(8), no 8, p. 1562-1572, SET-DEZ, 2012.

Rev. Elet. em Gestão, Educação e Tecnologia Ambiental (e-ISSN: 2236-1170)

\section{REFERÊNCIAS BIBLIOGRÁFICAS}

ALLAN, J. A. (1998) Virtual water: a strategic resource. Global solutions to regional deficits. Ground Water, v. 36, n. 4, p. 545-546.

ALLEN, R. G., PEREIRA, L. S., RAES, D. AND SMITH, M. (1998) 'Crop evapotranspiration: Guidelines for computing crop water requirements', FAO Irrigation and Drainage Paper 56, Food and Agriculture Organization, Rome

ANEEL/ANA (2001). Introdução ao gerenciamento de recursos hídricos. Brasília. ANEEL/ANA.

AQUASTAT - FAO's Information System on Water and Agriculture. Aquastat country database, consulta em http://www.fao.org/nr/water/aquastat/dbase/index.stm (consultado em 02/10/2010/08:11h).

CARMO, R. L., OJIMA, A. L. R. O., OJIMA, R, NASCIMENTO, T.T. (2007) Água virtual, escassez e gestão: $O$ Brasil como grande "exportador" de água. Revista Ambiente \& Sociedade, v.X, n.1,. p. 83-96.

CHAPAGAIN, A.K. and HOEKSTRA, A.Y. (2004) 'Water footprints of nations', UNESCO-IHE

CHAPAGAIN, A.K. and HOEKSTRA, AY (2004a). Water footprints of nations. Value of Water Research Report Series. UNESCO-IHE, v.1, n. 16, Nov, 80p.

CHAPAGAIN, A.K. and HOEKSTRA, AY (2004b) Water footprints of nations. Value of Water Research Report Series. UNESCO-IHE, v.2, n. 16, Nov, 240p.

CHAPAGAIN, A.K. and HOEKSTRA, A.Y. (2011) The blue, green and grey water footprint of rice from production and consumption perspectives, Ecological Economics, 70(4): 749-758.

ERCIN, A. E., ALDAYA M. M., and HOEKSTRA A. Y. (2011) The water footprint of soy milk and soy burger and equivalent animal products. Value of Water Res. Rep. Ser. №. 49. UNESCO-IHE, Delft, the Netherlands

FAO - Food and Agriculture Organization of the United Nations. 1961-2002. World Grain Production. Rome: FAO, Quarterly Bulletin of Statistics

GLEICK, P.H. (2000) The changing water paradigm: a look at twenty-first century water resources development, Water International 25(1):127-138.

HOEKSTRA, A.Y. (2007) Human appropriation of natural capital: Comparing ecological footprint and water footprint analysis, Value of Water Research Report Series $n^{\circ} .23$, UNESCO-IHE.

HOEKSTRA, A.Y. and CHAPAGAIN, A.K. (2007) Water footprints of nations: water use by people as a function of their consumption pattern, Water Resources Management. 21(1): 35-48.

HOEKSTRA, A.Y., CHAPAGAIN, A.K., ALDAYA, M.M. and MEKONNEN, M.M. (2009) Water footprint manual: State of the art 2009, Water Footprint Network, Enschede, the Netherlands.

HOEKSTRA, A.Y., CHAPAGAIN, A.K., ALDAYA, M.M. AND MEKONNEN, M.M. (2011) The water footprint assessment manual: Setting the global standard, Earthscan, London, UK. 
Rev. Elet. em Gestão, Educação e Tecnologia Ambiental (e-ISSN: 2236-1170)

HOEKSTRA, A.Y., HUNG, P.Q. (2005) Globalisation of water resources: international virtual water flows in relation to crop trade, Global Environmental Change,15(1): 45-56

HOEKSTRA, A.Y., MEKONNEN, M.M. (2012) The water footprint of humanity, Proceedings of the National Academy of Sciences, doi/10.1073/pnas.1109936109.

LLAMAS, M. R.; MARTINEZ SANTOS, P. (2006) Significance of the silent revolution of intensive groundwaters use in world water policy. In: Rogers, P. P.; Llamas, M. R.; Martinez Cortina, M. (Ed.). Water crisis: myth or reality? Espain: Funda-ción Marcelino Botín, Taylor \& Francis, 2006. p.163-80.

MEKONNEN, M.M. AND HOEKSTRA, A.Y. (2011) National water footprint accounts: the green, blue and grey water footprint of production and consumption. Value of Water Research Report Series No.50, UNESCO-IHE, Volume 1.

MEKONNEN, M.M. and HOEKSTRA, A.Y. (2010) The green, blue and grey water footprint of farm animals and animal products. Main Report, Volume 1.

MEKONNEN, M.M. AND HOEKSTRA, A.Y. (2011) The green, blue and grey water footprint of crops and derived crop products, Hydrology and Earth System Sciences, 15(5): 1577-1600.

MMA, Ministério do Meio Ambiente. Agenda 21, Secretaria de Articulação Institucional e Cidadania Ambiental, Conferência das Nações Unidas - Capítulo 18 [on line] Disponível em: http://www.mma.gov.br/sitio/index.php?ido=conteudo. monta\&idEstrutura=18\&idConteudo=861

OMM/UNESCO, Hay suficiente água em el mundo?, 1997.

PIMENTEL D, BERGER B, FILIBERTO D, NEWTON M, WOLFE B, KARABINAKIS E, CLARK S, POON E, ABBETT E, NANDAOPAL S. (2004) Water Resources: Agricultural and Environmental Issues. Bioscience, 54 (10), 909-918, Outubro.

ROPPA, L. (2006) Perspectivas da produção mundial de carnes, 2006 a 2030. Revista Pork World, n.34, p.16-27.

ROSEGRANT, M. W. AND RINGLER, C. (2000) Impact on food security and rural development of transferring water out of agriculture, Water Policy 1(6): 567-586.

TUNDISI, J. G. Recursos hídricos no futuro: problemas e soluções. Estud. av. São Paulo, v. 22, n. 63, 2008.

TUNDISI, J. G. Água no século XXI - enfrentando a escassez. São Carlos: Rima, 2003.

UERJ - Universidade do Estado do Rio de Janeiro, Declaração de Dublin, s.d., consulta em www.meioambiente.uerj.br/emrevista/documentos/dublin.htm (27/11/2010/9:00h).

UNESCO-IHE, Institute for Water Education: Annual Report, 2004

WWF - World Wide Fund For Nature, A Pegada Hídrica do Consumo, Relatório Planeta Vivo 2010. Brasil, agosto 2010. 